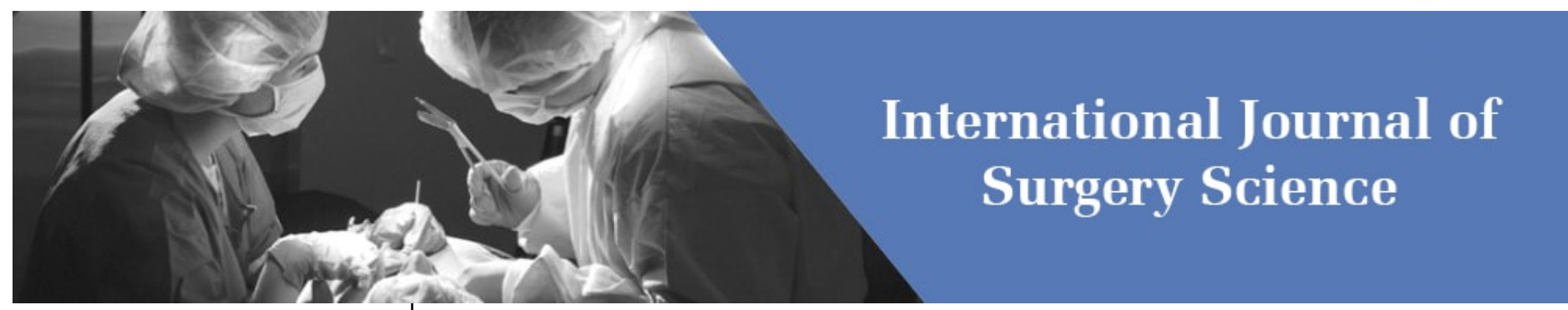

E-ISSN: 2616-3470

P-ISSN: 2616-3462

(C) Surgery Science

www.surgeryscience.com

2021; 5(1): 214-216

Received: 16-12-2020

Accepted: 02-02-2021

Dr. Faraz Zeeba

Assistant Professor, Department of General Surgery, Kanachur

Institute of Medical Sciences,

Mangalore, Karnataka, India
Corresponding Author:

Dr. Faraz Zeeba

Assistant Professor, Department of

General Surgery, Kanachur

Institute of Medical Sciences,

Mangalore, Karnataka, India

\section{A Study of clinical and surgical management of incisional hernia}

\section{Dr. Faraz Zeeba}

DOI: https://doi.org/10.33545/surgery.2021.v5.i1d.616

\section{Abstract}

Hernias are more likely after emergency surgery or surgery that requires a large incision. If the edges of the wound aren't properly aligned after surgery, the incision may not heal well, increasing the likelihood of a hernia. The sewing technique used to close the incision can also play a part. The most serious complications of incisional hernias are bowel obstruction and strangulation. A strangulated hernia can cause tissue death in your intestine. This condition may be life-threatening if you don't get treatment right away. It's also possible for hernias to rupture, but this is extremely rare. Small hernias that go untreated tend to get larger over time. If a hernia gets too big, it can cause swelling and pain in your abdomen and eventually become irreducible. You'll likely notice quickly if this happens because it tends to cause a lot of discomfort. If a hernia of any size causes significant pain or discomfort or has a negative effect on your quality of life, contact your healthcare provider right away. Complications can be potentially lifethreatening, so it's best to have any unusual symptoms looked at just in case.

Keywords: Incisional Hernia, Management, Clinical

\section{Introduction}

Incisional hernias can develop after abdominal surgery. They happen after up to 15 to 20 percent Trusted Source of abdominal operations involving incisions. Certain factors may increase or decrease your risk for developing an incisional hernia. Incisional hernias happen when the surgical cut in your abdominal wall doesn't close properly after surgery. This can cause your abdominal muscles to weaken, allowing tissue and organs to form a hernia.

Incisional hernia has followed abdominal surgery like a shadow for more than a century. Ian Aird defines incisional hernia as a diffuse extrusion of peritoneum and abdominal contents through a weak scar of an operation or accidental wound. Incisional hernia occurs in 5-11\% of patients subjected to abdominal operations. Many factors are associated with incisional hernia like age, sex, obesity, chest infections, type of suture material used and most important wound infection. ${ }^{1,2}$ Laparoscopic techniques of hernia repair have revolutionised the treatment of incisional hernia repair by reducing the morbidity and less hospital stay. This study has been undertaken to assess the magnitude of this problem, various factors leading to development of this condition and the different modalities of treatment practiced in our setup.

\section{Aims and Objectives}

To study the clinical and management of incisional hernia.

\section{Materials and Methods}

A total of 60 cases were studied. This study was done in Kanachur Institute of Medical Sciences, Mangalore.

This study was done from March 2019 to February 2020.

\section{Exclusion criteria}

Included patients beyond 70 years of age and incisional hernias associated with other abdominal wall hernias.

A detailed history of all the patients was taken and a thorough clinical examination was done to determine the type and cause of hernia. 


\section{Results}

Table 1: Age Distribution

\begin{tabular}{|l|l|}
\hline $30-40$ years & 06 \\
\hline $41-50$ years & 17 \\
\hline $51-60$ years & 03 \\
\hline $61-70$ years & 34 \\
\hline
\end{tabular}

Table 2: Sex Distribution

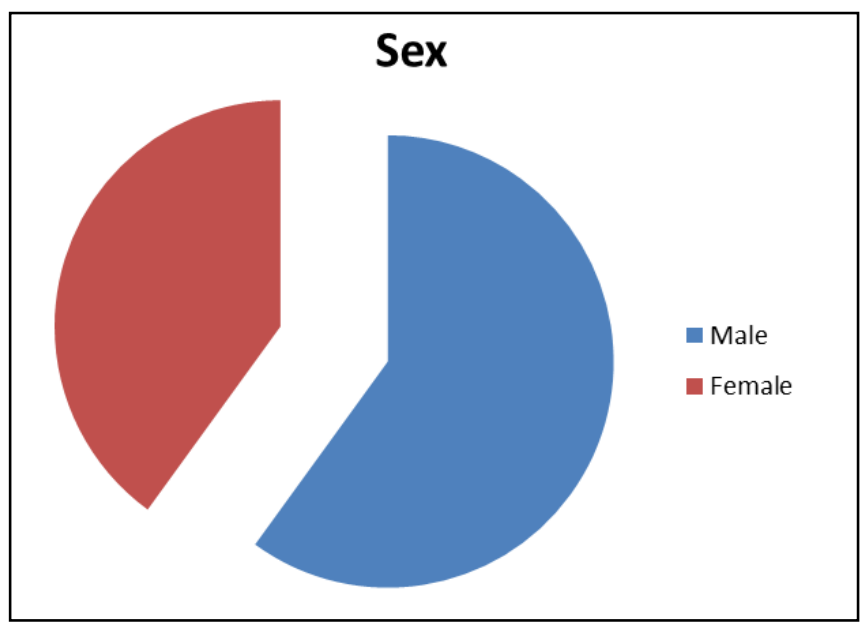

Table 3: Previous Surgeries

\begin{tabular}{|c|c|}
\hline Appendicectomy & 06 \\
\hline Hysterectomy & 02 \\
\hline Caesarean section & 14 \\
\hline Explorative laparotomy & 18 \\
\hline Cholecystectomy & 11 \\
\hline Miscellaneous & 09 \\
\hline
\end{tabular}

Table 4: Signs and Symptoms

\begin{tabular}{|c|c|}
\hline Abdominal swelling & 57 \\
\hline Pain & 37 \\
\hline Obstruction & 02 \\
\hline Fever & 14 \\
\hline
\end{tabular}

Table 5: Incision

\begin{tabular}{|c|c|}
\hline Lower midline & 41 \\
\hline Upper midline & 11 \\
\hline McBurney & 05 \\
\hline Paramedian & 02 \\
\hline Oblique lumbar & 01 \\
\hline
\end{tabular}

Table 6: Treatment

\begin{tabular}{|c|c|}
\hline Anatomical repair & 05 \\
\hline Onlay mesh & 05 \\
\hline Sublay mesh & 49 \\
\hline Underlay mesh & 01 \\
\hline
\end{tabular}

\section{Discussion}

Meticulous aseptic technique and careful closure of the abdominal wound is necessary to prevent incisional hernia. Proper preoperative preparation of the patients with high risk is an important factor in preventing recurrence of incisional hernia. Agrawal $\mathrm{M}$ et al. ${ }^{[3]}$ analysed 100 cases of incisional hernia, $42 \%$ of patients were in the age group 41-45 years, followed by 51-60 years (30\%), 31-40 years (17\%) and $21-30$ years $(11 \%)$. In a similar study done by Ellis et al. ${ }^{[4]} 48 \%$ of patients developing incisional hernia belonged to the age group of 31-40 years. The mean age of incisional hernia in the present study was 40.7 years, which was comparable with the study by Ellis et al. (49.4 years). In the study by Agrawal et al., female-to-male ratio was 1.6:1. In a similar study done by Ellis and Heddle, femaletomale ratio was 4.8:1. Millbourn et al. ${ }^{[5]}$ reported an incidence of $64.6 \%$ female population in their study of 383 patients. The reason behind this could be laxity of the abdominal muscles due to multiple pregnancies and increased number of lower abdominal incisions in females. J.B. Shah et al. ${ }^{[6]}$ and Goel et al. series have male-to-female ratio of $1: 1.17$ and $1: 1.25$, respectively. In the present study, male: female ratio was 1:6 being more common in females. On clinical examination in the study by Agrawal et al., $386 \%$ of cases presented with reducible lump, only three cases had severe pain with strangulation. Incisional hernia occurred between 6 months to 1 year of surgical intervention in $48 \%$ of cases. $68 \%$ patients had previous surgeries through lower abdominal incisions, $18 \%$ patients with upper midline incision, $10 \%$ patients with right paramedian incision and $4 \%$ with left paramedian incision. In the study by Bucknell et al., 42\% cases presented with hernia 1-5 years after primary surgery. $68 \%$ patients who had lower abdominal incisions developed incisional hernia followed by $18 \%$ patients with upper midline incision, $10 \%$ patients with right paramedian incision and 4\% with left paramedian incision. Millbourn et al. and Carlson found that this type of hernia is common in females undergoing gynaecological surgeries in which lower abdominal incisions are made [7]. Some authors believe that incisional hernia rates do not differ by type of incision and incision should be driven by surgeon's preference with respect to the patient's disease and anatomy. Ponka series ${ }^{[8]}$ stated that repeated surgeries (25\%) could be one of the risk factors in developing incisional hernia. In various studies $[9,10]$ wound infection following the surgery was the main factor for the development of incisional hernia. The other common factors were burst abdomen following infection and chronic cough during postoperative period. In a research done by Bose et al. ${ }^{[11]}$ in their study documented the common risk factors as wound infection in 53.63\% of cases, obesity in 30\% and COPD in $20.90 \%$. In the study by Agrawal et al., most common cause for incisional hernia was found to be postoperative infection (47\%), followed by cough (10\%) and early return to work (2\%). In the present study risk factors promoting incisional hernias was wound infection accounted for $40 \%$, obesity (30\%) and COPD in $8 \%$ of cases.

\section{Conclusion}

Prompt diagnosis and treatment is the need of the hour for such pathologies.

\section{References}

1. Bucknall TE, Cox PJ, Ellis H. Burst abdomen and incisional hernia: a prospective study of 1129 major laparotomies. $\mathrm{Br}$ Med J. 1982;284(6320):931-933.

2. Mudge $M$, Hughes LE. Incisional hernia: a 10 year prospective study of incidence and attitudes $\mathrm{Br} \mathrm{J}$ Surg. 1985;72(1):70-71.

3. Agrawal M, Singh H, Sharma SP et al. Prevalence, clinical presentation, and management of incisional hernia in the Indian population: a cross-sectional study, Int J Sci Stud. 2016;4(7):51-54.

4. Ellis H, Heddle R. Does the peritoneum need to be closed at laparotomy? Br J Surg. 1977;64(10):733- 736.

5. Millbourn D, Cengiz Y, Israelsson LA. Effect of stitch length on wound complications after closure of midline 
incisions: A randomized controlled trial Arch Surg. 2009;144(11):1056-1059.

6. Shah JB. Incisional hernia. A study of 50 cases, Indian Journal of Surgery. 1977;39:353-356.

7. Carlson MA. New developments in abdominal wall closure Chirurg. 2000;71(7):743-753.

8. Ponka JL. Hernias of the abdominal wall. 1st EDN. Philadelphia, London: WB Saunders 1980:186-190.

9. Seiler CM, Deckert A, Diener MK et al. Midline versus transverse incision in major abdominal surgery: a randomized, double-blind equivalence trial (POVATI: ISRCTN60734227). Ann Surg. 2009;249(6):913-920, Jebmh.com Original Research Article J. Evid. Based Med. Healthc., P-ISSN- 2349-2562, E-ISSN-2349-2570/Vol.4/ Issue 66/Aug. 17, 2017 Page 3952

10. Jenkins TP. The burst abdominal wound: a mechanical approach, Br J Surg. 1976;63(11):873- 876.

11. Bose SM, Lal Roshan, Kalra Manju et al. Ventral hernia-a review of 175 cases, Indian Journal of Surgery. 1999;61(3):180-184. 